5. Fu T., Cao H., Yin R. và cộng sự. (2018). Depression and anxiety correlate with diseaserelated characteristics and quality of life in Chinese patients with gout: a case-control study. Psychol Health Med, 23(4), 400-410.

6. Lower vitamin D levels are associated with depression in patients with gout. <https://www.ncbi.nlm.nih.gov/pmc/articles/PMC6 338117/>, accessed: 28/08/2021.

7. Pazcoguín J.M., Vargas M.A.S., và Manlapaz D. (2018). AB1457-HPR Aggression, depression level and gout-related characteristics among filipinos diagnosed with gouty arthritis: a crosssectional, multi-centre study. 1860.2-1860.

8. Prior J.A., Mallen C.D., Chandratre P. và cộng sư. (2016). Gout characteristics associate with depression, but not anxiety, in primary care: Baseline findings from a prospective cohort study. Joint Bone Spine, 83(5), 553-558.

9. Changchien T.-C., Yen Y.-C., Lin C.-L. và cộng sư. (2015). High Risk of Depressive Disorders in Patients With Gout. Medicine (Baltimore), 94(52).

\title{
DẤU ẤN HBcrAg HUYẾT THANH TRONG DIỄN BIẾN TỰ NHIÊN Ở BỆNH NHÂN VIẾM GAN VI RÚT B MẠN TẠI BỆNH VIỆN BACCH MAI
}

\author{
Nguyễn Vũ Hồng Vân*, Lê Thị Huyền*, Lê Thị Ngân**, \\ Trương Thái Phương**, Nguyễn Văn Dũng***
}

\section{TÓM TẮT}

Mục tiêu: Đánh giá nồng độ HBcrAg huyết thanh và tướng quan với các dấu ấn vi rút viêm gan $B$ trong các giai đoạn tự nhiên của viêm gan vi rút $B$ mạn. Phương pháp nghiên cứu: Nghiên cứu mô tả cắt ngang có phân tích tiến cứu 127 bệnh nhân viêm gan vi rút $B$ man chưa điều tri được theo dõi tai Trung tâm Bệnh Nhiệt đới Bệnh viện Bạch Mai. Kết quả: Nông đổ HBcrAg ở các giai đoạn nhiễm trùng man HBeAg dương tính (EPCI), viêm gan mạn $\mathrm{HBeAg}$ dương tính $(E P C H)$, nhiếm trùng mạn $\mathrm{HBeAg}$ âm tính (ENCI), viêm gan man $\mathrm{HBeAg}$ âm tính $(\mathrm{ENCH})$, thanh thái $\mathrm{HBsAg}$ (SC) lần lượt là $6,84 \pm 0,45 \mathrm{logU} / \mathrm{ml} ; 6,7 \pm 0,59$ $\log \mathrm{U} / \mathrm{ml} ; 3,15 \pm 0,86 \mathrm{log} / \mathrm{ml} ; 4,75 \pm 1,57 \quad \log \mathrm{U} / \mathrm{ml} ;$ $2,43 \pm 0,44 \log \mathrm{J} / \mathrm{ml}$. HBcrAg tương quan với HBV-DNA $(r=0,785 ; p=0,000)$, mạnh nhất ở giai đoạn EPCI $(r=0,988)$. HBcrAg tương quan với HBsAg ở mức độ trung bình $(r=0,653 ; p=0,00)$; tương quan với $A S T$, ALT trong giai đoạn ENCH với hệ số lần lượt $r=0,527$, $p=0,001$ và $r=0,335, p=0,049$. Ngoài ra, HBcrAg có thể phát hiện tới $75 \%$ trong nhóm thanh thải HBsAg. Kết luận: Nồng độ HB̉BcrAg phân bố khác nhau trong suốt các giai đoạn diễn biến tự nhiên của viêm gan vi rút B mạn. Nồng độ HBcrAg có mối tương quan mạnh với tải lượng HBV-DNA trong tất cả các giai đoạn, có thể phản ánh sự nhân lên của vi rút.

Từ khóa: Kháng nguyên liên quan đến lõi của vi rút viêm gan $B$ (HBcrAg); viêm gan vi rút $B$ mạn; diễn biến tự nhiên.

\section{SUMMARY \\ HEPATITIS B CORE-RELATED ANTIGEN IN THE NATURAL HISTORY OF CHRONIC}

*Truyền nhiễm và các bệnh Nhiệt đới trường ĐHY Hà Nội **Bệnh viện Bach Mai

***Trung tâm bệnh Nhiệt đới Bệnh viên Bạch Mai

Chịu trách nhiệm chính: Nguyễn Vũ Hồng Vân

Email: hongvan2181995@gmail.com

Ngày nhận bài: 9.7.2021

Ngày phản biên khoa học: 6.9.2021

Ngày duyệt bài: 13.9.2021
HEPATITIS B AT BACH MAI HOPITAL

Objectives: analyzing serum $\mathrm{HBcrAg}$ levels and correlation of $\mathrm{HBcrAg}$ with markers of hepatitis $B$ virus in the natural of chronic hepatitis B. Methods: Crosssectional descriptive prospective with analysis study of 127 treatment-naive chronic hepatitis B patients monitored at the Tropical Diseases Center of Bach Mai hospital. Results: HBcrAg levels in the groups of Hepatitis B e antigen (HBeAg)-positive chronic infection (EPCI), HBeAg-positive chronic hepatitis $(\mathrm{EPCH})$, HBeAg-negative chronic infection (ENCI), HBeAg-negative chronic hepatitis (ENCH), Hepatitis B $\mathrm{s}$ antigen (HBsAg) clearance (SC) were $6.84 \pm 0.45$ $\log \mathrm{U} / \mathrm{ml} ; \quad 6.7 \pm 0.59 \operatorname{logU} / \mathrm{ml} ; 3.15 \pm 0.86 \log \mathrm{U} / \mathrm{ml}$; $4.75 \pm 1.57 \mathrm{logU} / \mathrm{ml} ; 2.43 \pm 0.44 \mathrm{logU} / \mathrm{ml}$, respectively. The overall correlation of HBcrAg with HBV-DNA was strong in this study $(r=0.785 ; p=0.000)$, the strongest in the EPCI group $(r=0.988)$. The correlation of HBcrAg with HBsAg was moderate $(r=0.653 ; p=0.00)$. Correlation of HBcrAg with AST, ALT in the ENCH group were $r=0.527, p=0.001$ and $r=0.335, p=0.049$, respectively. In addition, $\mathrm{HBcrAg}$ was detectable up to $75 \%$ in the SC group. Conclusion: Serum HBcrAg levels are distributed differently groups in the natural of chronic hepatitis B. The correlation HBcrAg with HBV-DNA was strong in all groups, HBcrAg may as valuable marker for virus replication.

Keywords: Hepatitis B core-related antigen (HBcrAg); chronic hepatitis B virus; in the natural history.

\section{I. ĐẶT VẤN ĐỀ}

Nhiễm vi rút viêm gan $B$ (Hepatitis $B$ virus: HBV) mạn là mối đe dọa sức khỏe toàn câu nghiêm trọng. Theo báo cáo năm 2017 của Tổ chức Y tế thế giới, ước tính năm 2015 toàn cầu có khoảng 257 triệu người nhiễm HBV mạn và 884.400 người tử vong, trong đó có $30 \%$ tử vong do xơ gan và $40 \%$ tử vong do ung thư biểu mô tế bào gan ${ }^{1}$. Mặc dù hiện nay có nhiều loại thuốc điều trị viêm gan $B$ nhưng lại không thể 
loại bỏ hoàn toàn HBV, do sự tồn tại của DNA vòng đóng hóa trị (Covalently closed circular DNA - cccDNA) và HBV-DNA tích hợp vào $A D N$ tê bào gan. Chính vì thế, nồng độ cccDNA trong tế bào gan phản ánh hoat động sao chép của HBV và việc sinh thiết tế bào gan là tiêu chuẩn chính xác nhất đánh giá hoạt động của vi rút'․ Tuy nhiên trên thực hành lâm sàng, sinh thiết tế bào gan không thể thực hiện thường quy để đánh giá hoạt động của tể bào gan, mà đánh giá thông qua tải lượng HBV-DNA huyết thanh, định lượng $\mathrm{HBsAg}, \mathrm{HBeAg}$, anti-HBe, men gan ${ }^{3}$. Một xét nghiệm mới ra đời là kháng nguyên liên quan đến Iõi vi rút viêm gan $B$ (Hepatitis B corerelated antigen: $\mathrm{HBcrAg}$ ) bao gồm 3 protein của kháng nguyên core/pre-core là $\mathrm{HBeAg}, \mathrm{HBcAg}$, p22cr ${ }^{4}$. HBcrAg được báo cáo có mối tương quan tốt với cccDNA trong tế bào gan $(r=0.929$, $\mathrm{p}<0.001$ ), là một dấu ấn tương quan với hoạt động bệnh, ứng dụng để theo dõi điều trị ở những bệnh nhân đang dùng thuốc, dự báo nguy cơ xơ gan, ung thư gan ${ }^{4}$. Đối với những bệnh nhân chưa điều trị thuốc kháng vi rút thì đặc điểm, vai trò của $\mathrm{HBcAg}$ còn chưa thực sự sáng tỏ. Vì vậy, chúng tôi đã thực hiện nghiên cứu:"Dấu ấn HBcrAg huyết thanh trong diễn biến tự nhiên ở bệnh nhân viêm gan vi rút $B$ mạn tại bệnh viện Bạch Mai". Với mục đích đánh giá nồng độ $\mathrm{HBcrAg}$ huyết thanh trong các giai đoạn tự nhiên của HBV mạn và tương quan giữa HBcrAg với các dấu ấn vi rút khác ở một nhóm bệnh nhân HBV mạn chưa điều trị kháng vi rút được chẩn đoán và theo dõi tại BV Bạch Mai.

\section{II. ĐỐI TƯợNG VÀ PHƯƠNG PHÁP NGHIÊN CỨU}

2.1 Đối tượng nghiên cứu: Gồm 127 bệnh nhân được chẩn đoán là HBV mạn chưa điều trị được khám và theo dõi tại Trung tâm Bệnh nhiệt đới - Bệnh viện Bạch Mai từ tháng 8/2020 đển tháng 7/2021.

\subsection{Phương pháp nghiên cứu}

2.2.1 Phương pháp nghiên cứu: Mô tả cắt ngang

\subsubsection{Tiêu chuân lưa chon:}

- Bệnh nhân $\geq 16$ tuổi được chẩn đoán nhiễm HBV man theo tiêu chuẩn của Hướng dẫn chẩn

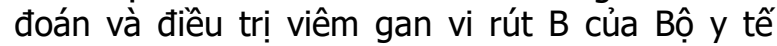
Việt Nam năm $2019^{3}$

- Chưa điều trị thuốc kháng vi rút

- Đồng ý tham gia nghiên cứu

\subsubsection{Tiêu chuẩn loại trừ:}

- Bệnh nhân đồng nhiễm với các vi rút viêm gan khác (viêm gan C...)

- Bệnh nhân đồng nhiễm với HIV.

2.2.4 Các chỉ tiêu nghiên cứu
- Các bệnh nhân được đánh giá về tuổi, giới và đánh giá cận lâm sàng qua các xét nghiệm hóa sinh (AST, ALT, bilirubin toàn phần, albumin), xét nghiệm vi sinh (HBsAg định lượng, $\mathrm{HBeAg}$, anti-HBe, HBV-DNA, HBcrAg)

- Dựa vào kết quả phân loại 127 bệnh nhân thành 5 nhóm:

+ Giai đoạn EPCI: Dấu ấn HBsAg dương tính, HBeAg dương tính, tải lượng HBV-DNA rất cao, men gan bình thường, không có triệu chứng lâm sàng.

+ Giai đoạn EPCH: Dấu ấn HBsAg dương tính, $\mathrm{HBeAg}$ dương tính, tải lượng HBV-DNA thấp hơn giai đoạn EPCI, men gan tăng.

+ Giai đoạn ENCI: Dấu ấn HBsAg dương tính, HBeAg âm tính, anti-HBe dương tính, tải lượng HBV-DNA không phát hiện hoặc thấp <10 copies/ml, men gan bình thường.

+ Giai đoạn ENCH: Dấu ấn HBsAg dương tính, HBeAg âm tính, anti-HBe dương tính, tải lượng HBV-DNA được phát hiện, men gan tăng.

+ Giai đoạn SC: bệnh nhân đã có HBsAg dương tính được ghi nhận tại phòng khám của chúng tôi ít nhất 6 tháng và đã thanh thải $\mathrm{HBsAg}$ trong quá trình theo dõi, và sau đó $\mathrm{HBsAg}$ âm tính liên tục với có hoặc không có sự xuất hiện của kháng thể anti-HBs.

\subsection{Xét nghiệm}

*Xét nghiệm HBcrAg huyết thanh: bao gồm 3 protein được mã hóa bởi vùng $\mathrm{preC} / \mathrm{C}$, có chung một chuỗi 149 acid amin giống hệt nhau bao gồm: $\mathrm{HBeAg}, \mathrm{HBCAg}$ và $\mathrm{p} 22 \mathrm{cr}$. Xét nghiệm $\mathrm{HBcrAg}$ được đo bằng máy Lumipulse $\mathrm{G} 1200$ với kỹ thuật CLIEA (Chemiluminescence enzyme immunoassay) sử dụng chất phát quang hóa học AMPPD để định lượng dựa trên liên kết kháng nguyên - kháng thể. Mẫu huyết thanh được thêm dung dịch xử lý để bất hoạt anti-HBc, antiHbe và phá bỏ cấu trúc phân tử vi rút, làm biểu lộ các kháng nguyên. Phạm vi đo lường của xét nghiệm này là từ $100 \mathrm{U} / \mathrm{ml}(2 \log \mathrm{U} / \mathrm{ml})$ đến $10.000 .000 \mathrm{U} / \mathrm{ml}(7 \mathrm{log} \mathrm{U} / \mathrm{ml})$. Xét nghiệm được thực hiện tại khoa vi sinh Bệnh viện Bạch Mai.

*Xét nghiệm HBV-DNA: Được định lượng bởi kĩ thuật real time-PCR trên máy PCR-Realtime COBAS ${ }^{2}$ TaqMan48 Analyzer, phầm mềm AMPLILINK phiên bản 3.2.0 (Roche - Thụy Sĩ). Ngưỡng phát hiện là $20 \mathrm{copies} / \mathrm{ml}$. Xét nghiệm được thực hiên tại khoa vi sinh Bv Bach Mai.

*Xét nghiệm định lượng $\mathrm{HBsAg:}$ Là xét nghiệm miển dịch sử dụng công nghệ vi hoạt hóa phát quang CMI (Chemiluminescent Microparticle Immuno Assay), sử dụng Cobas 8000 (Roche - Hitachi). Ngưỡng phát hiện là 0,05 IU/ml (50 IU/L). Xét nghiệm được thực hiện 
tại khoa vi sinh Bệnh viện Bạch Mai

* Xét nghiệm HBeAg / Anti-HBe: Sử dụng kỹ thuật miễn dịch điện hóa phát quang (Electro chimi luminescence immuno assay - ECLIA) trên máy Cobas 8000 (Roche - Hitachi)

*Xét nghiệm sinh hóa (AST, ALT, bilirubin, albumin,..) được đo theo máy xét nghiệm Cobas8K2 hoặc máy AU5800 tại khoa hóa sinh bệnh viện Bạch Mai.

\subsection{Quản lý và phân tích số liệu}

- Số liệu được nhập và xử lý theo chương trình xử lý số liệu SPSS 25

- Dùng các thuật toán thống kê y học:

+ Giá trị trung bình, độ lệch, trung vị, min, max, tứ phân vị

+ Thuật toán khi bình phương, so sánh tỷ lệ

+ Tính hệ số tương quan
III. KẾT QUẢ NGHIÊN CỨU

\section{1 Đặc điểm nhóm nghiên cứu}

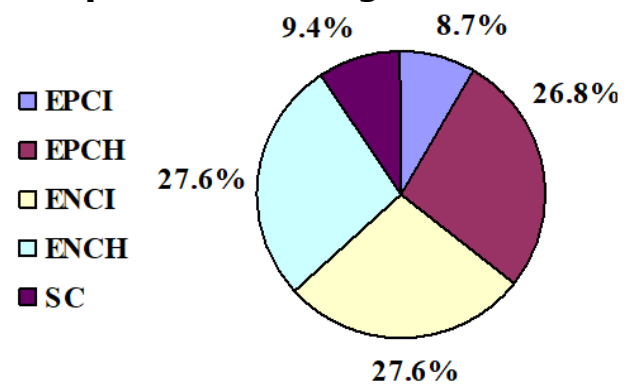

Biêu đồ 1: Phân bố các giai đoạn

Có 127 bệnh nhân tham gia nghiên cứu được chia thành 5 giai đoạn EPCI, EPCH, ENCI, ENCH, SC lần lượt có số bệnh nhân tham gia là $11(8,7 \%)$; 34 (26,8\%); 35(27,6\%); 35(27,6\%); 12(9,4\%).

Bảng 1: Đặc điểm nhân khẩu và cận lâm sàng

\begin{tabular}{|c|c|c|c|c|c|c|c|}
\hline \multirow[b]{2}{*}{ Đặc điểm } & \multirow{2}{*}{$\begin{array}{c}\text { Tổng } \\
\text { (n= 127) }\end{array}$} & \multicolumn{2}{|c|}{ HBeAg (+) } & \multicolumn{2}{|c|}{ HBeAg (-) } & \multirow[b]{2}{*}{$S C(n=12)$} & \multirow[b]{2}{*}{$\mathbf{p}$} \\
\hline & & $\begin{array}{c}\text { EPCI } \\
(n=11)\end{array}$ & $\begin{array}{c}\text { EPCH } \\
(n=34)\end{array}$ & $\begin{array}{c}\text { ENCI } \\
(n=35)\end{array}$ & $\begin{array}{c}\text { ENCH } \\
(n=35)\end{array}$ & & \\
\hline $\begin{array}{c}\text { Tuổi } \\
\text { Mean } \pm \text { SD } \\
(\text { min-max })\end{array}$ & $\begin{array}{c}43,49 \pm \\
14,5 \\
(18-80)\end{array}$ & $\begin{array}{c}28,73 \pm \\
7,76 \\
(19-40)\end{array}$ & $\begin{array}{c}37,06 \pm \\
11,7 \\
(18-71)\end{array}$ & $\begin{array}{c}41,09 \\
\pm 11,67 \\
(23-78)\end{array}$ & $\begin{array}{c}55 \pm \\
11,88 \\
(30-80)\end{array}$ & $\begin{array}{c}48,67 \pm \\
16,4 \\
(26-73)\end{array}$ & 0,000 \\
\hline $\begin{array}{c}\text { Giới nam } \\
(\mathrm{n}, \%)\end{array}$ & $87(66,9)$ & $6(54,5)$ & $26(76,5)$ & $22(62,9)$ & $23(65,7)$ & $8(66,7)$ & 0,654 \\
\hline $\begin{array}{c}\text { AST } \\
\text { Median(IQR) }\end{array}$ & $\begin{array}{c}44 \\
(23-257)\end{array}$ & $\begin{array}{c}29 \\
(22-30)\end{array}$ & $\begin{array}{c}114 \\
(49-1007)\end{array}$ & $\begin{array}{c}23 \\
(19-28)\end{array}$ & $\begin{array}{c}232 \\
(56-474)\end{array}$ & $\begin{array}{c}20,5 \\
(19-24)\end{array}$ & 0,000 \\
\hline $\begin{array}{c}\text { ALT (U/I } \\
\text { Median(IQR) }\end{array}$ & $\begin{array}{c}49 \\
(26-182)\end{array}$ & $\begin{array}{c}28 \\
(24-36)\end{array}$ & $\begin{array}{c}104 \\
(53-1396)\end{array}$ & $\begin{array}{c}25 \\
(18-30)\end{array}$ & $\begin{array}{c}113 \\
(60-838)\end{array}$ & $\begin{array}{c}22 \\
(12,5-30)\end{array}$ & 0,000 \\
\hline $\begin{array}{l}\text { Albumin } \\
\text { Mean } \pm \text { SD } \\
\text { (min-max) }\end{array}$ & $\begin{array}{c}40,29 \pm \\
7,03 \\
(19-48,8)\end{array}$ & $\begin{array}{c}44,13 \pm \\
2,45 \\
(40,4-48,5)\end{array}$ & $\begin{array}{c}38,66 \pm \\
7,49 \\
(20,4-47,3)\end{array}$ & $\begin{array}{c}44,79 \pm \\
3,38 \\
(29,6-48,8)\end{array}$ & $\begin{array}{c}35,46 \pm \\
7,38 \\
(19-46,7)\end{array}$ & $\begin{array}{c}41 \pm \\
5,79 \\
(27,1-46,4)\end{array}$ & 0,000 \\
\hline $\begin{array}{c}\text { Bilirubin } \\
\text { Median(IQR) }\end{array}$ & $\begin{array}{c}12,5 \\
(9-36,5)\end{array}$ & $\begin{array}{c}10,1 \\
(7,9-11,6)\end{array}$ & $\begin{array}{c}30 \\
(10,5-204)\end{array}$ & $\begin{array}{c}10 \\
(7,7-12,5)\end{array}$ & $\begin{array}{c}33,4 \\
(12,7-148)\end{array}$ & $\begin{array}{c}10,8 \\
(6-13)\end{array}$ & 0,000 \\
\hline $\begin{array}{l}\text { HBV DNA } \\
\text { Mean } \pm \text { SD } \\
(\min -\max )\end{array}$ & $\begin{array}{c}5,25 \pm \\
3,05 \\
(0-9,77) \\
\end{array}$ & $\begin{array}{c}8,19 \pm 1,86 \\
(2,89-9,25)\end{array}$ & $\begin{array}{c}7,15 \pm \\
2,07 \\
(0-9,07) \\
\end{array}$ & $\begin{array}{c}3,81 \pm \\
2,08 \\
(0-8,67)\end{array}$ & $\begin{array}{c}5,75 \pm \\
2,57 \\
(0-9,77) \\
\end{array}$ & $\begin{array}{c}0,15 \pm \\
0,52 \\
(0-1,81)\end{array}$ & 0,000 \\
\hline $\begin{array}{l}\text { HBsAg Mean } \pm \\
\text { SD (min-max) }\end{array}$ & $\begin{array}{l}5,2 \pm 2,15 \\
(0-7,97)\end{array}$ & \begin{tabular}{|c|}
$7,11 \pm 0,8$ \\
$(5,07-7,97)$
\end{tabular} & $\begin{array}{l}6,4 \pm 0,96 \\
(4,59-7,66)\end{array}$ & $\begin{array}{c}5,38 \pm 0,92 \\
(3-6,61)\end{array}$ & $\begin{array}{c}5,51 \pm 0.96 \\
(3,3-7,28)\end{array}$ & 0 & 0,000 \\
\hline
\end{tabular}

Mean: Giá trị trung bình; SD: độ lệch chuẩn; Min: Giá trị nhỏ nhất; Max: Giá trị lớn nhất; Median: Trung vị; IQR: tứ phân vị; Tuổi (năm), AST(U/l), ALT $(\mathrm{U} / \mathrm{l})$, Albumin $(\mathrm{g} / \mathrm{l})$, Bilirubin (mmol/l) HBV-DNA log10 copies/ml; HBsAg logIU/L

- Quần thể nghiên cứu có tỷ lệ nam giới cao hơn nữ giới với $66,9 \%$ nam và $33,1 \%$ nữ. Tỷ lệ nam và nữ trong các giai đoạn viêm gan không có sự khác biệt.

- Độ tuổi trung bình của quần thể nghiên cứu là 43,49 $\pm 14,5$ (năm), thấp nhất là 18 tuổi, cao nhất là 80 tuổi. Độ tuổi trung bình giữa các giai đoạn có sự khác biệt
- Đặc điểm xét nghiệm sinh hóa được mô tả cụ thể ở Bảng 1. Men gan, bilirubin tăng trong giai đoạn $\mathrm{EPCH}$ và $\mathrm{ENCH}$.

- Nồng độ trung bình của tải lượng HBV-DNA, HBsAg định lượng của quần thể nghiên cứu lần lượt là $5,25 \pm 3,05$ (log copies $/ \mathrm{ml}) ; 5,2 \pm 2,15$ ( $\log \mathrm{IU} / \mathrm{L})$. Nhìn chung, nồng độ trung bình đều cao nhất ở nhóm EPCI sau đó đến EPCH, ENCH, ENCI, SC.

\section{2 Đặc điểm của HBcrAg}

- Trong số 127 bệnh nhân, HBcrAg có sự khác nhau đáng kể và phân bố rộng rãi giữa các giai đoạn nhiếm HBV khác nhaú. HBcrAg nằm 
trong khoảng từ 2 đến $7 \log \mathrm{U} / \mathrm{ml}$, với mức trung bình là 4,79 $1,09 \log \mathrm{U} / \mathrm{ml}$.

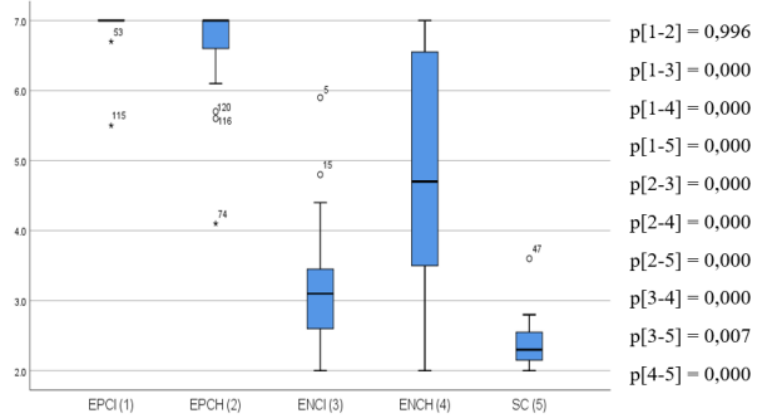

Biểu đồ 2: Phân bố HBcrAg $(\log \mathrm{V} / \mathrm{m} /)$ và so sánh trung binh ở các giai đoan

- Giai đoạn EPCI, mức trung bình của $\mathrm{HBcrAg}$ là $6,84 \pm 0,45 \log \mathrm{U} / \mathrm{ml}$ (trung vị $7 \log \mathrm{U} / \mathrm{ml}$, khoảng 5,5-7 log $/ / \mathrm{ml})$. Giai đoạn $\mathrm{EPCH}$, có trung bình $6,7 \pm 0,59 \log / \mathrm{ml}$ (trung vị $7 \mathrm{log} / \mathrm{ml}$, khoảng 5,1-7 logU/ml). Không có sự khác biệt về phân bố giữa 2 giai đoạn này $(p=0,996)$.

- Giai đoạn ENCI, ENCH có mức trung bình (trung vị) lần lượt là $3,15 \pm 0,86(3,1 ; 2-5,9)$ $\log \mathrm{U} / \mathrm{ml} ; 4,75 \pm 1,57(4,7 ; 2-7) \log \mathrm{U} / \mathrm{ml}$. Có sự khác biệt về phân bố HBcrAg giữa các giai đoạn này với nhau và khác biệt với $E P C I, E P C H$ từng đôi một $(p<0,05)$, theo biểu đồ 2 .

- 12 bệnh nhân trong giai đoạn SC có nồng độ trung bình của HBcrAg là 2,43 $\pm 0,44$ $\log \mathrm{U} / \mathrm{ml}$. (trung vị 2,3; khoảng 2-3,6 $\log \mathrm{U} / \mathrm{ml}$ ). Trong đó, có $1 / 12(8,3 \%)$ bệnh nhân có tải lượng vi rút được phát hiện với giá trị 1,81 log copies/ml, 11 bệnh nhân còn lại có tải lượng vi rút dưới ngưỡng. Có $3 / 12$ bệnh nhân dưới ngưỡng phát hiện (2 log $/ / \mathrm{ml})$, tức là có tới $9 / 12$ (75\%) bệnh nhân trong nhóm này được phát hiện bằng xét nghiệm HBcrAg huyết thanh.

\subsection{Tương quan của HBcrAg}

Bảng 2: Tương quan HBcrAg với các đặc điểm của bệnh nhân

\begin{tabular}{|c|c|c|c|c|c|c|c|c|c|c|}
\hline \multirow{2}{*}{$\begin{array}{c}\text { †ẳc } \\
\text { điểm }\end{array}$} & \multicolumn{2}{|c|}{ Tổng } & \multicolumn{2}{c|}{ EPCI } & \multicolumn{2}{c|}{ EPCH } & \multicolumn{2}{c|}{ ENCI } & \multicolumn{2}{c|}{ ENCH } \\
\cline { 2 - 10 } & $\mathbf{r}$ & $\mathbf{p}$ & $\mathbf{r}$ & $\mathbf{p}$ & $\mathbf{r}$ & $\mathbf{p}$ & $\mathbf{r}$ & $\mathbf{p}$ & $\mathbf{r}$ & $\mathbf{p}$ \\
\hline Tuổi & $-0,245$ & 0,006 & $-0,185$ & 0,586 & $-0,02$ & 0,911 & $-0,228$ & 0,188 & 0,24 & 0,89 \\
\hline AST & 0,376 & 0,000 & $-0,170$ & 0,617 & $-0,255$ & 0,145 & 0,236 & 0,173 & 0,527 & 0,001 \\
\hline ALT & 0,366 & 0,000 & $-0,363$ & 0,272 & $-0,261$ & 0,135 & 0,216 & 0,212 & 0,335 & 0,049 \\
\hline Albumin & $-0,177$ & 0,053 & 0,11 & 0,976 & 0,286 & 0,106 & 0,019 & 0,914 & $-0,099$ & 0,595 \\
\hline Bilirubin & 0,32 & 0,000 & 0,352 & 0,353 & $-0,02$ & 0,913 & 0,022 & 0.901 & 0,312 & 0,077 \\
\hline HBV DNA & 0,785 & 0,000 & 0,988 & 0,000 & 0,345 & 0,049 & 0,416 & 0,013 & 0,78 & 0,000 \\
\hline HBSAg & 0,604 & 0,000 & 0,119 & 0,744 & 0,444 & 0,03 & 0,256 & 0,158 & 0,31 & 0,123 \\
\hline
\end{tabular}

- Trong toàn bộ bệnh nhân nghiên cứu, mối tương quan giữa nồng độ $\mathrm{HBcrAg}$ và tải lượng HBV-DNA rất mạnh $(r=0,785 ; p=0,000)$; mối tương quan giữa nồng độ $\mathrm{HBcrAg}$ và nồng độ HBsAg định lượng thấp hơn $(r=0,604 ; p=0,000)$. Mối tương quan yếu giữa nồng độ $\mathrm{HBcrAg}$ và nồng độ AST, ALT, bilirubin toàn phần với hệ số tương quan lần lượt là $r=0,376 ; 0,366 ; 0,32$ và $p=0,000$ nhưng không thây mối tương quan với nồng độ albumin trong máu.

- Ớ giai đoạn HBeAg dương tính đều có mối tương quan giữa nồng độ $\mathrm{HBcrAg}$ và tải lượng HBV-DNA. Tuy nhiên ở giai đoạn EPCI có mối tương quan mạnh với hệ số $r=0,988(p=0,000)$ trong khi đó tương quan yếu hơn ở giai đoạn EPCH với hệ số $r=0,345(p=0,049)$. Ngược lại, đối với tương quan giữa nồng độ $\mathrm{HBcrAg}$ và nồng độ $\mathrm{HBsAg}$ huyết thanh chỉ thấy ở giai đoạn EPCH $(r=0,444 ; p=0,03)$ mà không tương quan ở giai đoạn EPCI. Ngoài ra, khi HBeAg dương tính thì không thấy bất kì mối tương quan nào giữa nồng độ $\mathrm{HBcrAg}$ huyết thanh với tuổi, nồng độ transaminase, bilirubin toàn phần, nồng độ albumin trong máu ở cả 2 giai đoạn.
- Mối tương quan giữa nồng độ $\mathrm{HBcrAg}$ với tải lượng HBV-DNA khá mạnh ở giai đoạn ENCH $(r=0,78 ; p=0,000)$ và cũng có tương quan ở giai đoạn ENCI với hệ số tương quan thấp hơn $\mathrm{r}=$ 0,$416 ; p=0,013$. Cả 2 giai đoạn này đều không có tương quan giữa nồng độ $\mathrm{HBcrAg}$ với nồng độ HBsAg huyết thanh. Đối với các chỉ số tuổi và sinh hóa, chỉ thấy mối tương quan giữa nồng độ $\mathrm{HBCrAg}$ và $A S T, A L T$ trong nhóm ENCH với hệ số tương quan lần lượt là $r=0,527 ; p=0,001$ và $r=0,335 ; p=0,049$.

\section{BÀN LUẬN}

Dấu ấn huyết thanh học và tải lượng vi rút là những công cụ chính để chẩn đoán và quản lý HBV mạn và để phân tầng nguy cơ xơ gan, $\mathrm{HCC}$, quyết định điều trị kháng vi-rút và theo dõi đánh giá hiệu quả điều trị. Trong nghiên cứu này, chúng tôi đã cung cấp phân bố nồng độ $\mathrm{HBcrAg}$ ở nhóm bệnh nhân nhiếm HBV mạn chưa điều trị kháng vi rút và mối tương quan của $\mathrm{HBcrAg}$ với các dấu ấn khác trong các giai đoạn diễn biến tự nhiên của nhiễm HBV mạn.

Trong nghiên cứu, nồng độ HBcrAg có sự 
khác biệt rõ rệt giữa bệnh nhân nhiễm HBV mạn HBeAg dương tính và ầm tính. Bệnh nhân nhiếm HBV mạn HBeAg dương tính có mức nồng độ $\mathrm{HBcrAg}$ cao hơn so với bênh nhân nhiếm HBV mạn HBeAg âm tính (Biểu đồ 2). Điều này liên quan đến việc giảm dần sản xuất $\mathrm{HBeAg}$ sau khi chuyển đổi huyết thanh HBeAg. Ở nhóm HBeAg dương tính, nồng độ $\mathrm{HBcrAg}$ trung bình ở giai đoạn EPCI và EPCH trong nghiên cứu của chúng tôi lần lượt là $6,84 \log \mathrm{U} / \mathrm{ml} ; 6,7 \log \mathrm{U} / \mathrm{ml}$; và không có sự khác biệt giữa 2 giai đoạn này $(p=0,996)$. 2 nghiên cứu lớn trước đây, ở Châu A của Seto $(n=404)^{5}$ và ở Châu Âu $(n=249)^{6}$ chỉ ra có sự khác biệt nồng độ $\mathrm{HBcrAg}$ giữa 2 giai đoạn, có thể do nghiên cứu của chúng tôi không pha loãng tiếp nối để xác định nồng độ chính xác nhất của HBcrAg khi giá trị mẫu huyết thanh ở giới hạn trên của phạm vi đo lường là $7 \mathrm{log} \mathrm{U} / \mathrm{ml}$. Đối với nhóm bệnh nhân nhiễm HBV mạn HBeAg âm tính, nồng độ $\mathrm{HBcrAg}$ nhóm ENCI thấp hơn đáng kể so với nhóm ENCH (3,15 logU/ml so với $4,75 \log \mathrm{U} / \mathrm{ml}, \mathrm{p}=0,000)$. Điều này có liên quan đến hoạt động viêm hoại tử và xơ hóa đáng kể hơn ở nhóm ENCH. Nồng độ $\mathrm{HBCrAg}$ cả 2 giai đoạn này đều $>3 \log \mathrm{U} / \mathrm{ml}$, vậy thì không thể dùng mốc $3 \log \mathrm{U} / \mathrm{ml}$ để phân biệt $\mathrm{ENCH}$ và $\mathrm{ENCI}$ như nghiên cứu trước ${ }^{6}$.

Nhiêu nghiên cứu đã chỉ ra nồng độ $\mathrm{HBcrAg}$ huyết thanh tương quan mạnh với các dấu ấn hoạt động của HBV trong gan? ${ }^{7}$. Nghiên cứu này của chúng tôi cũng chứng minh được mối tương quan tốt với tải lươnng HBV-DNA ở tổng thể và ở các giai đoạn bệnh. Trong đó tương quan mạnh nhất ở giai đoạn EPCI với hệ số tương quan $r=0,988(p=0,000)$. Như vậy, nồng độ HBcrAg có thể phản ánh một phần sự nhân lên của HBV. Chúng tôi tìm thây mối tương quan của nồng $\mathrm{HBcrAg}$ với nồng độ $\mathrm{HBsAg}$ trong cả quần thể nghiên cứu với $r=0,604(p=0,000)$; nhưng khi xét trong từng giai đoạn chỉ thấy tương quan xảy ra ở giai đoạn $\mathrm{EPCH}(r=0,444, p=0,03)$. Nghiên cứu ở châu Á năm $2014^{5}$ cũng không thây mối tương quan với nồng độ HBsAg trong các giai đoạn; khác với nghiên cứu ở Châu Âu $2015^{6}$. Liệu có thể giải thích được điều này dựa vào kiểu gen HBV khác nhau ở những người châu Á (chủ yếu $B, C$ ) so với người châu Âu $(A, D)$. Mức độ tăng transaminase phản ánh tổn thương tế bào gan, khi đó cho phép HBV từ tế bào gan xâm nhập vào máu. Tuy nhiên, nồng độ $\mathrm{HBcrAg}$ có tường quan với ALT, AST trong giai đoạn $\mathrm{ENCH}$ và không tương quan trong giai đoan $\mathrm{EPCH}$. Như vậy, có thể $\mathrm{HBeAg}$ ảnh hưởng đển mối tương quan giữa $\mathrm{HBcrAg}$ và men gan.
Giai đoạn thanh thải $\mathrm{HBsAg}, \mathrm{HBcrAg}$ được phát hiện ở $75 \%$ số bệnh nhân, con số này cao hơn nhiều so với những nghiên cứu khác ${ }^{7}$. Có thể là cỡ mẫu của chúng tôi trong giai đoạn này còn bé, nên có sự chênh lệch lớn. Trong nghiên cứu này chưa phân tích được nồng độ của $\mathrm{HBCrAg}$ so với thời gian thanh thải $\mathrm{HBsAg}$ và khả năng tái hoạt ở giai đoạn này, vì vậy chúng tôi sẽ tiếp tục theo dõi và đánh giá thêm ở giai đoạn thanh thải HBsAg tự nhiên trong thời gian tới.

\section{KẾT LUÂN}

Nồng độ HBcrAg thay đổi đáng kể trong các giai đoạn diễn biến tự nhiên của HBV mạn. Đặc biệt khi nhiếm HBV mạn HBeAg âm tính, nồng độ $\mathrm{HBCrAg}$ có sự khác biệt giữa nhóm ENCI và ENCH, gợi ý cho chúng ta có thể sử dụng $\mathrm{HBcrAg}$ là một công cụ để phân biệt 2 giai đoạn này với nhau.

ở những bệnh nhân HBV mạn, sau khi thanh thải HBsAg thường được xem như khỏi bệnh, tuy nhiên vẫn có nguy cơ bùng phát viêm gan nhất là trong những trường hợp điều trị hóa chất, các thuốc ức chế miễn dịch,... hoặc tiến triển biến chứng xơ gan, ung thư gan. HBcrAg vẫn được phát hiện ở một số bệnh nhân trong giai đoạn SC, vì vậy $\mathrm{HBcrAg}$ nên được nghiên cứu tiến cứu lâu dài để đánh giá các yếu tố nguy cơ xảy ra.

Tuy ở nghiên cứu này không thể đánh giá được tương quan của HBcrAg với cccDNA trong tế bào gan, nhưng rõ ràng tương quan của HBcrAg và tải lượng HBV-DNA huyết thanh là mạnh trong tất cả các giai đoạn HBV mạn tự nhiên. Như vậy HBcrAg là dấu hiệu hữu ích đánh giá sự nhân lền của HBV.

\section{TÀI LIẸU THAM KHẢO}

1. WHO. Global hepatitis report.

2. Terrault NA, Bzowej NH, Chang K-M, Hwang JP, Jonas MM, Murad MH. AASLD Guidelines for Treatment of Chronic Hepatitis B. Hepatol Baltim Md. 2016;63(1):261-283. doi:10.1002/hep.28156

3. Bộ y tế. Hướng dẫn chẩn đoán điêu trị bệnh viêm gan vi rút B. Published online 2019.

4. Chen E-Q, Feng $S$, Wang $M-L$, et al. Serum hepatitis B core-related antigen is a satisfactory surrogate marker of intrahepatic covalently closed circular DNA in chronic hepatitis B. Sci Rep. 2017;7. doi:10.1038/s41598-017-00111-0

5. Seto W-K, Wong DK-H, Fung J, et al. Linearized hepatitis $\mathrm{B}$ surface antigen and hepatitis $B$ core-related antigen in the natural history of chronic hepatitis B. Clin Microbiol Infect Off Publ Eur Soc Clin Microbiol Infect Dis. 2014;20 (11):1173-1180. doi:10.1111/1469-0691.12739

6. Maasoumy B, Wiegand SB, Jaroszewicz J, et al. Hepatitis B core-related antigen (HBcrAg) levels in the natural history of hepatitis $B$ virus infection in a large European cohort predominantly infected with genotypes $A$ and $D$. Clin Microbiol Infect Off 
Publ Eur Soc Clin Microbiol Infect Dis. 2015;21(6):606.e1-10.

doi:10.1016/j.cmi.2015.02.010

7. Mak L-Y, Wong DK-H, Cheung K-S, Seto W-K, Lai C-L, Yuen M-F. Review article: hepatitis B core-related antigen ( $\mathrm{HBcrAg})$ : an emerging marker for chronic hepatitis $B$ virus infection. Aliment Pharmacol Ther. 2018;47(1):43-54. doi:10.1111/apt.14376

\title{
KẾT QUẢ ĐIỀU TRỊ PHẪU THUÂT U ĐĂC GIẢ NHÚ Ở THÂN ĐUÔI TUỴ TẠI BÊ̂NH VIÊ̂N VIÊTT ĐỨC
}

\author{
Nguyễn Minh Trọng*, Nguyễn Kiều Hưng*, Phạm Bá Đức*, \\ Nguyễn Thị Khuyên*, Phạm Hoàng Hà**, Trịnh Hồng Sơn**
}

\section{TÓM TẮT}

Mục tiêu: Kết quả điều trị phẫu thuật $u$ đặc giả nhú ở thân đuôi tuy tai Bệnh viện Việt Đức. Đối tượng và phương pháp: nghiên cứu mô tả cắt ngang trên 24 bệnh nhân được chẩn đoán u đặc giả nhú ở thân đuôi tuy được điều trị phẫu thuật bệnh viên Viêt Đức từ 01/2016 đến 12/2020. Kết quả: Tuổi trung bình mắc u đặc giả nhú tuy là $24 \pm 10,2$ tuổi (7 - 45 tuổi), chủ yếu là nữ $(91,7 \%)$, tỷ lê nam/nữ là $1 / 11$. Lý do vào viện do đau bụng $(62,5 \%)$ là chủ yếu. Thời gian trung bình phát hiện bệnh là 3,7 tháng. Triệu chứng đau bụng chiếm $75,0 \%$, sờ thấy u chiếm $8,3 \%$. Đặc điểm cắt lớp vi tính thây u chủ yếu ở thân tuy $(45,8 \%)$, cấu trúc dạng đặc $(70,8 \%)$ và kích thước u trung bình là $5,8 \pm 2,56 \mathrm{~cm}(2,3-11,7)$. Mổ nội soi có 4 trường hợp chiếm 16,7\%. Phẫu thuật cắt thân đuôi tuy kèm lách (50,0\%). 62,5\% bệnh nhân làm HMMD khẳng đinh u đăc giả nhú. Kết luân: u đăc giả nhú của tụy được xếp là u tụy ngoại tiết ác tính khi có độ loan sản cao. Phẩu thuật vấn là phương pháp điều trị chính và thời gian sống thêm sau mổ cao.

Tứ khoá: u đặc giả nhú, phẫu thuật cắt u tuy.

\section{SUMMARY}

RESULTS OF SURGICAL RESECTIONS FOR SOLID PSEUDOPAPILLARY NEOPLASMS IN THE BODY AND TAIL OF PANCREAS AT VIET DUC HOSPITAL

Objectives: Results of surgical treatment of solid pseudopapillary neoplasms (SPN) in the body and tail of the pancreas at Viet Duc Hospital. Subjects and methods: A cross-sectional descriptive study on 24 patients diagnosed with SPN in the body and tail of the pancreas who were operated at Viet Duc hospital from January 2016 to December 2020. Results: Of the 24 patient; 22 (91.7\%) were females and 2 $(8.3 \%)$ were males, ratio of males/females was $1 / 11$. The mean age of SPN was $24 \pm 10.2$ years old (range, 7 - 45 years). The main reason for admission was

*Bệnh viện $K$

** Bênh viện HN Việt Đức

Chịu trách nhiệm chính: Nguyễn Minh Trọng

Email: drtrong81@gmail.com

Ngày nhận bài: 8.7.2021

Ngày phản biên khoa họ: 3.9.2021

Ngày duyệt bài: 10.9.2021 abdominal pain $(62.5 \%)$. The mean time to diagnosis was 3.7 months. Abdominal pain $(75.0 \%)$, palpable tumor $(8.3 \%)$. The computed tomography features showed that the tumor was mainly in the body of the pancreas $(45.8 \%)$, solid structure $(70.8 \%)$ and mean diameters of SPN was $5.8 \pm 2.56 \mathrm{~cm}$ (range, $2.3-$ $11.7 \mathrm{~cm}$ ). Surgical treatment included pancreatosplenectomy in 12 patients, spleenpreserving distal pancreatectomy in 6 pantients $(25 \%)$, enucleation in $6(25 \%)$ without any complications. Laparoscopic surgery had 4 cases (16.7\%). $62.5 \%$ of patients had IHC to confirm SPN. Conclusion: SPN are classified as malignant exocrine pancreatic tumors when there is a high degree of dysplasia. Surgical resections remain the mainstay of treatment and survival after surgery is high. Regular monitoring for early detection of recurrence and metastasis also has a timely treatment attitude.

Keywords: solid pseudopapillary tumor, pancreatectomy

\section{I. ĐĂT VẤN ĐỀ}

U đặc giả nhú của tuy. (Solid pseudopapillary neoplasms - SPN) là một khối u tụy ngoại tiết hiếm gặp, chiếm khoảng $1 \%$ trong u tụy, được Gruber Frantz mô tả lần đâu tiên vào năm 1959. $U$ còn mang tên "Frantz tumor" cho đến năm 1996 khi Tổ chức Y tế Thế giới đưa ra khái niệm "u đặc giả nhú" của tụy [1]. Nguồn gốc chưa rõ, có nhiều giả thuyết về nguồn gốc SPN: (1) từ tế bào gốc đa chức năng; (2) từ tế bào tụy ngoại tiết; (3) từ tế bào liên quan đến mào sinh dục [1].

Bệnh thường gặp ở phụ nữ trẻ gốc Á và Phi, tỷ lệ nam/nữ là 1:10, tuổi trung bình khi đi khám là 22 tuổi, thường không có triệu chứng [1]. Trước đây, u được xếp loại u giáp biên (WHO 2002). Từ năm 2010, WHO [2] đã xếp SPN có loạn sản cao vào nhóm ung thư tụy ngoại tiết và phẫu thuật là phương pháp điêu trị chính khi u chưa di cắn với tỷ lệ sống sau 5 năm là 97\% [1].

Chính vì vậy, bài viết này chứng tôi mong muốn đánh giá kết quả điều trị phẫu thuật u đặc giả nhú ở thân - đuôi tuy tại Bệnh viện HN Việt Đức từ 01/2016 đến 12/2020. 